\title{
The Prevalence and Determinants of Unintended Pregnancies Among Women in Abakaliki, Southeast Nigeria
}

\author{
L. O. Lawani ${ }^{1}$, N. N. Ekem ${ }^{1}$, R. C. Onoh ${ }^{1}$, J. N. Eze ${ }^{1}$, K. C. Ekwedigwe ${ }^{1}$, J. O. Egede ${ }^{1} \&$ M. E. Isikhuemen ${ }^{2}$ \\ ${ }^{1}$ Department of Obstetrics and Gynaecology, Federal Teaching Hospital, Abakaliki, Nigeria \\ ${ }^{2}$ Department of Obstetrics and Gynecology, University of Benin Teaching Hospital, Benin, Nigeria \\ Correspondence: Isikhuemen, M. E., Department of Obstetrics and Gynecology, University of Benin Teaching \\ Hospital, Benin, Nigeria.
}

Received: May 21, 2018 Accepted: August 24, 2018 Online Published: September 6, 2018

doi:10.5539/gjhs.v10n10p65 URL: https://doi.org/10.5539/gjhs.v10n10p65

\begin{abstract}
Background: Unintended pregnancy is a major social and public health problem affecting women within the reproductive age group. It jeopardizes women's sexual and reproductive health and may pose a threat to the achievement of Sustainable Development Goal 3. Objective: To determine the prevalence and determinants of unintended pregnancy in Abakaliki, Southeast Nigeria.
\end{abstract}

Methods: A semi-structured questionnaire was used for a cross-sectional survey of antenatal clinic attendees at the Federal Teaching Hospital, Abakaliki from January 2015 to March 2015. A total of 185 questionnaires were correctly filled and analyzed using 2008 Epi Info version statistical software (Atlanta Georgia, USA).

Results: Out of the 185 antenatal clinic attendees, 43.8\% (81/185) reported having had an unintended pregnancy at some point in their lives. The age at marriage, level of education, place of residence, sex education and use of contraception were significant determinants of unintended pregnancy.

Conclusion: The prevalence of unintended pregnancy in this study was high. Its determinants include educational status, use of contraception, age at marriage and place of residence.

Keywords: determinants, Nigeria, prevalence, unintended pregnancy

\section{Introduction}

Pregnancy is a source of ecstasy and euphoria to women, families, communities and the nation at large. However, pregnancy intention at the time of conception has an impact on the health and wellbeing of the mother, unborn baby, and indeed the entire family (Mutumbi, 2013). As such, pregnancy can be intended or unintended depending on the woman's desire at the time of conception (Mutumbi, 2013). Hence, unintended pregnancy is a major social and public health problem affecting women in both developing and developed countries (Palamuleni \& Adebowale, 2014). It may jeopardize maternal and child health and wellbeing (Palamuleni \& Adebowale, 2014). Indeed, unintended pregnancy increases health and socio-economic risks for children, women, men, families and the society at large (Palamuleni \& Adebowale, 2014; Ikamari, Izugbara, \& Ochako, 2013). Therefore, it could be an encumbrance to the achievement of Sustainable Development Goal (SDG) (Ikamari, Izugbara, \& Ochako, 2013).

Unintended pregnancy comprises mistimed and unwanted pregnancy (Mutumbi, 2013; Palamuleni \& Adebowale, 2014; Ikamari et al., 2013; Habte, Teklu, Melese, \& Magafu, 2013; Izugbara, 2014). A mistimed pregnancy is said to occur when a woman becomes pregnant at a time when she does not want to be (Mutumbi, 2013; Palamuleni \& Adebowale, 2014; Habte, Teklu, Melese, \& Magafu, 2013; Izugbara, 2014). That is, she becomes pregnant earlier than she desires (Mutumbi, 2013; Palamuleni \& Adebowale, 2014; Habte et al., 2013; Izugbara, 2014). On the other hand, an unwanted pregnancy is said to occur when a woman becomes pregnant when she never intends to ever become pregnant or when she does not want to have any more child (Mutumbi, 2013; Palamuleni \& Adebowale, 2014; Habte et al., 2013; Izugbara, 2014). Unintended pregnancy therefore is a pregnancy which continuation could compromise the physical, psychological, religious, economic and/or socio-cultural wellbeing of the mother, the unborn child and /or the family. The level of unintended pregnancy serves as an indicator of the state of women's reproductive health and of the degree of women's autonomy in making reproductive decisions (Palamuleni \& Adebowale, 2014; Geda \& Lako, 2011).

All sexually active women of reproductive age are at risk of having unintended pregnancy (Palamuleni \& 
Adebowale, 2014; Izugbara, 2014). The prevalence of unintended pregnancy varies from place to place depending on people's sexual behaviour and contraceptive acceptance and use. In sub-Saharan Africa, unintended pregnancy accounted for about $39 \%$ of the 49 million pregnancies that occurred in 2008 (Faye et al., 2013). In Nigeria about one in three women of reproductive age had experienced an unplanned pregnancy (Sudhinaraset, 2008). However, the recently published Nigeria Demographic and Health survey of 2013 reported a prevalence of $9 \%$ (National Population Commission (Nigeria) and ICF International, 2014). The high rates of unintended pregnancy are driven by non-use, incorrect and inconsistent use of contraceptive methods and contraceptive method failure and less commonly sexual coercion and rape (Mutumbi, 2013; Palamuleni \& Adebowale, 2014; Izugbara, 2014).

Globally, improving access to family planning services will prevent about 52 million unintended pregnancies annually (Izugbara, 2014). It could also prevent about 1.5 million maternal and child death annually and decrease the number of induced abortion by $64 \%$ (Izugbara, 2014). Improved access to contraception also has the potential of reducing the complications associated with pregnancies and preserve 27 million healthy life years (Izugbara, 2014).

In view of dearth of work on unintended pregnancy in our environment, the study was carried out to determine the prevalence and determinants of unintended pregnancy in Abakaliki. The findings of this study would help guide reproductive health program planners and policy makers to understand various factors influencing unintended pregnancy. They would also assist in the implementation of the reproductive health program which would reduce unintended pregnancy as well as its attendant risk of maternal and perinatal morbidity and mortality.

\subsection{Aim and Obectives of the Study}

The aim of this study is to determine the prevalence and determinants of unintended pregnancies among women in Abakaliki. The specific objectives of the study were:

1) To find out the prevalence of unintended pregnancies among women in Abakaliki.

2) To ascertain the determinants of unintended pregnancies in the studied population.

\section{Methodology}

\subsection{Study Area}

The study was carried out at the Antenatal clinic of the Federal Teaching Hospital, Abakaliki (FETHA), Ebonyi State, Southeast Nigeria. The Federal Teaching Hospital is the only tertiary hospital in Ebonyi state. It was formed in 2012 from the merger between the former Federal Medical Centre (FMC), Abakaliki and then Ebonyi State University Teaching Hospital (EBSUTH), Abakaliki. It is located in Abakaliki, the state capital and receives referral from all parts of the state and neighbouring states of Benue, Enugu, Cross River and Abia.

\subsection{Study Design}

The study was an observational cross-sectional study that was conducted at the Antenatal clinic of FETHA over a three month period from January to March 2015. The participants were pregnant women who came for antenatal care.

\subsection{Sample Size}

The sample size was calculated using the formula: $N=Z^{2} P Q / D^{2}$

Where:

$\mathrm{N}$ is the sample size

$\mathrm{Z}$ is a constant for standard normal deviate which is 1.96 at $95 \%$ confidence interval.

$\mathrm{P}$ is the prevalence of unintended pregnancy which was 9\% according to NDHS, 2013 (National Population Commission (Nigeria) and ICF International, 2014).

$\mathrm{Q}$ is 1-P

$\mathrm{D}$ is the error margin which was $\mathrm{P} / 2(4.5 \%)$ because the prevalence was less than $10 \%$ (Naing, Winn, \& Rusli, 2006).

Therefore,

$$
\mathrm{N}=\frac{1.96^{2} \times 0.09 \times(1-0.09)}{0.045^{2}}
$$

$\mathrm{N}=155$. Applying an attrition rate of $20 \%$ gave a minimum sample size of 186 . 


\subsection{Sampling Technique}

The participants were selected using systematic sampling method. The antenatal clinic registers were used to assign numbers to the pregnant women. The first participant was selected using simple random technique and then every third person was selected. The participants were adequately counselled on the study and their concerns if any were addressed. An informed consent was obtained from each of the participants. A well-structured pre-tested questionnaire was used for data collection. Each questionnaire contained 25 questions organized into 3 sections covering the socio-demographic data, prevalence and determinants of unintended pregnancies. The chief researcher and 2 trained research assistants who were senior house officers of the department administered the questionnaires to the participants while awaiting to be attended to. The participants filled the questionnaire and submitted them back to the researcher or the research assistants. Those that are not literate were assisted by the research assistants.

\subsection{Inclusion Criteria}

The following inclusion criteria were used to select the research participants:

Pregnant women attending antenatal clinic at FETHA

Pregnant women who gave informed consent to participate in the study

Clinically stable pregnant women

\subsection{Exclusion Criteria}

The following women were excluded from the study:

Clinically unstable patients

Pregnant women who did not give consent to participate in the study

\subsection{Data Analysis}

The statistical analysis was carried out using 2008 Epi Info statistical software (Atlanta Georgia, USA). Descriptive analysis was used for the socio-demographic characteristics of the respondents and other variables. Logistic regression was used to assess the association between some selected variables and the experience of unintended pregnancy at level of significance $\mathrm{P}<0.05$.

\subsection{Ethical Consideration}

Approval and ethical clearance were obtained from the Ethical and Research Committee of FETHA before embarking on the study.

\section{Results}

Of the 186 questionnaires administered, 185 (99.5\%) were correctly filled, returned and analyzed.

Table1 shows the socio-demographic characteristics of the respondents and its relationship with the pregnancy intentions. The overall prevalence of unintended pregnancies in this study was $43.8 \%(81 / 185)$ as shown in Figure 1. The majority of the respondents $33.0 \%(61 / 185)$ were within $25-29$ years of age. The highest percentage of unintended pregnancies $75 \%$ (3/4) occurred in women within 45 - 49 years age group followed by those within 15 -19 years age group, $71.4 \%(5 / 7)$ and those within 40 - 44 years age group, $70 \%(7 / 10)$. The women within $20-24$ years age group had the least percentage, $30.8 \%(12 / 39)$ of unintended pregnancies.

Most of the women $91.4 \%$ (169/185) were currently married at the time of the survey while those who were separated or divorced were the least group $1.1 \%(2 / 185)$. Of the women who were ever married, most of them $77.5 \%(138 / 178)$ were married at 18 years of age and above. The highest percentages of unintended pregnancies occurred among those who were single $85.7 \%(6 / 7)$ and those who got married before 18 years of age $67.5 \%$ $(27 / 40)$.

Women of Roman catholic denomination had the highest percentage $48.8 \%$ (42/86) of unintended pregnancy. Also, the majority $44.9 \%(83 / 185)$ of the respondents had tertiary education while the least number of respondents $5.4 \%$ $(10 / 185)$ had no formal education. The highest percentage $70 \%(7 / 10)$ of unintended pregnancies occurred in those with no formal education while the least percentage $25.3 \%$ (21/83) occurred in those with tertiary education. Again, the majority of the women $68.1 \%(126 / 185)$ lived in the urban area. However, the percentage of unintended pregnancies was higher $59.3 \%(35 / 59)$ among the rural dwellers.

Table 2 shows the number of episodes of unintended pregnancies and the period of occurrence with respect to the marital status. The majority $48.1 \%$ (39/81) of the women had only a single episode of unintended pregnancy and 
the majority $56.8 \%$ (46/81) of them also had the unintended pregnancies only before marriage.

Table 1. Socio-demographic characteristics and pregnancy intentions

\begin{tabular}{|c|c|c|c|}
\hline Variables & N (185) (\%) & $\begin{array}{l}\text { Intended Pregnancy } \\
\text { n (104) (\%) }\end{array}$ & $\begin{array}{l}\text { Unintended Pregnancy } \\
\text { n (81) (\%) }\end{array}$ \\
\hline \multicolumn{4}{|l|}{ Age } \\
\hline $15-19$ & $7(3.8)$ & $2(28.6)$ & $5(71.4)$ \\
\hline $20-24$ & $39(21.1)$ & $27(69.2)$ & $12(30.8)$ \\
\hline $25-29$ & $61(33)$ & $37(60.0)$ & $24(40.0)$ \\
\hline $30-34$ & $39(21.1)$ & $22(56.4)$ & $17(43.6)$ \\
\hline $35-39$ & $25(13.5)$ & $12(48.0)$ & $13(52.0)$ \\
\hline $40-44$ & $10(5.4)$ & $3(30.0)$ & $7(70.0)$ \\
\hline $45-49$ & $4(2.2)$ & $1(25.0)$ & $3(75.0)$ \\
\hline \multicolumn{4}{|l|}{ Marital status } \\
\hline Single & $7(3.8)$ & $1(14.3)$ & $6(85.7)$ \\
\hline Married & $169(91.4)$ & $97(57.4)$ & $72(42.6)$ \\
\hline Separated/divorced & $2(1.1)$ & $2(100.0)$ & $0(0.0)$ \\
\hline Widowed & $7(3.8)$ & $4(57.1)$ & $3(42.9)$ \\
\hline \multicolumn{4}{|l|}{ Age at marriage } \\
\hline$<18$ years & $40(22.5)$ & $13(32.5)$ & $27(67.5)$ \\
\hline$\geq 18$ years & $138(77.5)$ & $89(64.5)$ & $49(35.5)$ \\
\hline \multicolumn{4}{|l|}{ Religion } \\
\hline Catholic & $86(46.5)$ & $44(51.2)$ & $42(48.8)$ \\
\hline Non-catholic & $93(50.3)$ & $56(60.2)$ & $37(39.8)$ \\
\hline Muslim & $5(2.8)$ & $3(60.0)$ & $2(40.0)$ \\
\hline Traditionalist & $1(0.5)$ & $1(100)$ & $0(0.0)$ \\
\hline \multicolumn{4}{|l|}{ Education } \\
\hline None & $10(5.4)$ & $3(30.0)$ & $7(70.0)$ \\
\hline Primary & $25(13.5)$ & $10(40.0)$ & $15(60.0)$ \\
\hline Secondary & $67(36.2)$ & $29(43.3)$ & $38(56.7)$ \\
\hline Tertiary & $83(44.9)$ & $62(74.7)$ & $21(25.3)$ \\
\hline \multicolumn{4}{|l|}{ Residence } \\
\hline Urban & $126(68.1)$ & $80(63.5)$ & $46(36.5)$ \\
\hline Rural & $59(31.9)$ & $24(40.7)$ & $35(59.3)$ \\
\hline
\end{tabular}

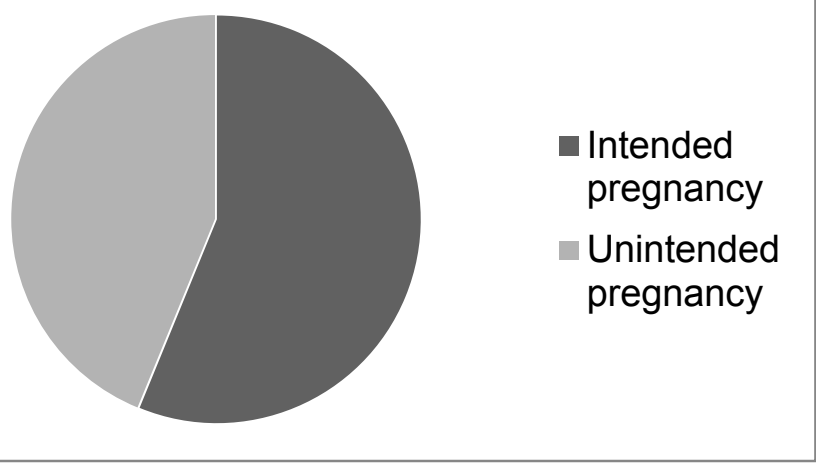

Figure 1. Prevalence of unintended pregnancies 
Table 2. The number and marital stage of occurrence of unintended pregnancies

\begin{tabular}{lll}
\hline Variable & No. $(\mathbf{8 1})$ & $\mathbf{\% ( 1 0 0 )}$ \\
\hline No of unintended pregnancies & 39 & 48.1 \\
One & 33 & 40.1 \\
Two & 9 & 11.1 \\
More than two & & \\
\hline When & 46 & 56.8 \\
Before marriage only & 26 & 32.1 \\
After marriage only & 9 & 11.1 \\
Both before and after marriage & & \\
\hline
\end{tabular}

Table 3 shows the reasons given by the respondents for categorizing the pregnancies as unintended. The commonest reason (35.4\%) for regarding the pregnancy as unintended was because of being single at the time the pregnancy occurred. Other common reasons stated were being in school $(20.4 \%)$, wanted to space child birth $(13.6 \%)$, not wanted by the partner $(12.2 \%)$ and being too young $(10.9 \%)$. The other less common reasons were as stated in Table 3 below.

Table 3. **Reasons for the unintended pregnancies

\begin{tabular}{lll}
\hline Reasons & No. (147) & \% (100) \\
\hline Single & 52 & 35.4 \\
In school & 30 & 20.4 \\
Not wanted by partner & 18 & 12.2 \\
Wanted to space child birth & 20 & 13.6 \\
Completed family size & 8 & 5.4 \\
No money to care for it & 1 & 0.7 \\
Too young & 16 & 10.9 \\
Resulted from extramarital affair & 1 & 0.7 \\
Because of my health & 1 & 0.7 \\
Because of my job & 0 & 0 \\
\hline
\end{tabular}

** Multiple entries allowed.

Table 4 shows the contraceptive use and sex education of the respondents and its relationship with pregnancy intentions. The majority $87.5 \%(161 / 185)$ of the women had heard of contraceptive methods and the majority $77.8 \%(144 / 185)$ of them also had used one method of contraception or the other. The women who had not heard of contraception had higher percentage $66.7 \%$ (16/24) of unintended pregnancy. Similarly, those women who had not used any contraceptive method had higher percentage $85.4 \%$ (35/41) of unintended pregnancy. Again, of the women who had unintended pregnancy, only $14.8 \%(12 / 81)$ were using contraceptive method when they conceived. Of these women who conceived while on contraception, only a minority $25 \%(3 / 12)$ of them were using modern method of contraception (male condom and injectables) while the rest $75 \%(9 / 12)$ were using natural method (withdrawal method, Billing's method and calendar method). Furthermore, the majority 59.5\% (110/185) of the women did not receive sex education and higher percentage $69.1 \%(76 / 110)$ of unintended pregnancies occurred in those that did not receive sex education.

Table 5 shows the reasons given by the respondents for not using contraceptive methods. The commonest reason (34.9\%) stated by the respondents for not using any contraceptive method was that there was no need for it. This was followed by the fear of side effects $(18.6 \%)$, religious reasons (18.6\%) and lack of knowledge about contraceptive method (14.0\%). The other less common reasons were as shown in Table 5. 
Table 4. Contraceptive use and sex education with pregnancy intentions

\begin{tabular}{|c|c|c|c|}
\hline Variable & $\mathbf{N}(185)(\%)$ & $\begin{array}{l}\text { Intended pregnancies } \\
\text { n (\%) }\end{array}$ & $\begin{array}{l}\text { Unintended pregnancies } \\
\text { n (\%) }\end{array}$ \\
\hline \multicolumn{4}{|l|}{ Heard of FP } \\
\hline Yes & $161(87.5)$ & $96(59.6)$ & $65(40.4)$ \\
\hline No & $24(12.5)$ & $8(33.3)$ & $16(66.7)$ \\
\hline \multicolumn{4}{|l|}{ Ever used FP } \\
\hline Yes & $144(77.8)$ & $79(54.9)$ & $65(45.1)$ \\
\hline No & $41(25.5)$ & $6(14.6)$ & $35(85.4)$ \\
\hline \multicolumn{4}{|c|}{ Using FP when conceived } \\
\hline Yes & $12(14.3)$ & & \\
\hline No & $72(85.7)$ & & \\
\hline \multicolumn{4}{|c|}{ FP method used when conceived } \\
\hline Modern method & $3(25)$ & & \\
\hline Natural method & $9(75)$ & & \\
\hline \multicolumn{4}{|c|}{ Received sex education? } \\
\hline Yes & $75(40.5)$ & $60(80.0)$ & $15(20.0)$ \\
\hline No & $110(59.5)$ & $34(30.9)$ & $76(69.1)$ \\
\hline
\end{tabular}

Table 5. Reasons for not using contraceptive methods

\begin{tabular}{lll}
\hline$* *$ Reasons & $\mathbf{N}(\mathbf{4 3})$ & $\mathbf{\% ( 1 0 0 )}$ \\
\hline Fear of side effects & 8 & 18.6 \\
I did not where to access it & 2 & 4.7 \\
Religious reasons & 8 & 18.6 \\
I did not have money to buy it & 1 & 2.3 \\
I am not at risk & - & - \\
My partner refused & 3 & 7.0 \\
There was no need for it & 15 & 34.9 \\
I did not have much knowledge about it & 6 & 14.0 \\
\hline
\end{tabular}

** Multiple entries allowed.

Table 6 below shows the logistic regression analysis for the determinants of unintended pregnancies. It showed that the factors that were significantly associated with the likelihood of having unintended pregnancies after controlling the confounders were age at marriage (odds ratio $0.201,95 \%$ confidence interval $0.053-0.763 ; P=$ 0.02 ), educational level (odds ratio $0.226,95 \%$ confidence interval0.088-0.579; $P<0.01$ ), residential place (odds ratio $4.280,95 \%$ confidence interval 1.148-15.956; $P=0.03$ ), sex education (odds ratio $0.216,95 \%$ confidence interval $0.046-0.347, P<0.01$ ) and contraceptive use (odds ratio $0.361,95 \%$ confidence interval $0.145-0.901, \mathrm{P}=$ $0.03)$. 
Table 6. Unconditional logistic regression analysis for determinants of unintended pregnancies

\begin{tabular}{lllll}
\hline Variables & Odds ratio & $\begin{array}{l}\mathbf{9 5 \%} \text { CI for odds } \\
\text { ratio }\end{array}$ & $\begin{array}{l}\text { Regression } \\
\text { coefficient }\end{array}$ & P-value \\
\hline Age & 0.178 & $0.030-1.049$ & -1.727 & 0.06 \\
Marital status & 0.746 & $0.035-15.786$ & -0.293 & 0.85 \\
Age at marriage & 0.201 & $0.053-0.763$ & -1.607 & $0.02^{* *}$ \\
Education & 0.226 & $0.088-0.579$ & -1.488 & $<0.01^{* *}$ \\
Residence & 4.280 & $1.148-15.956$ & 1.454 & $0.03^{* *}$ \\
Sex education & 0.126 & $0.046-0.347$ & -2.074 & $<0.01^{* *}$ \\
Contraceptive use & 0.361 & $0.145-0.901$ & -1.019 & $0.03^{* *}$ \\
Constant & $*$ & $*$ & 2.074 & 0.168 \\
\hline
\end{tabular}

$\mathrm{CI}=$ confidence interval, $* *$ Statistically significant.

\section{Discussion}

Unintended pregnancy is an avoidable social and public health problem that pervade both developing and developed countries with no cultural, racial, religious, socio-economic or geographical limitations. It is a common occurrence. The prevalence of $43.8 \%$ found in this study which was quite high lent credence to this fact. This implies that more than 2 in 5 women in Abakaliki has had unintended pregnancy at some point in their lives. This was higher than the national prevalence of $9 \%$ according to the Nigeria Demographic and Health Survey (NDHS) of 2013 (National Population Commission (Nigeria) and ICF International, 2014). This could be because the unintended pregnancies reported in NDHS were gotten only from those who currently pregnant at the time of the survey and those who had pregnancies within 5 years preceding the survey. It was also higher than $24.3 \%$ and $31.7 \%$ reported by Oye-Adeniran et al in Lagos and Edo states respectively about a decade ago (Oye-Adeniran et al., 2004). However, it was similar to the prevalence found in other studies (Ikamari et al., 2013; Geelheod et al., 2002), but lower than the prevalence reported in some other African ${ }^{1}$ and western countries (Goto, Yasumura, Reich, \& Fukao, 2002; Finer \& Zolna, 2011).

About half of the women had only an episode of unintended pregnancy. This could be because such women after having the unintended pregnancy took precautionary measures such as using contraception to avoid its recurrence. It could also be that some of them were single when they had the unintended pregnancy and subsequently got married because more than half of the women had the unintended pregnancies before marriage. That could explain why only about one-tenth of them had more than two episodes of unintended pregnancies.

The commonest reason for regarding the pregnancy as unintended was being single at the time the pregnancy occurred. This could be because of the socio-cultural implication of premarital conception in our society. However, Oye-Adeniran et al in a similar study found that the need for child spacing was the commonest reason for regarding the pregnancy as unintended (Oye-Adeniran et al., 2004). Also, being in school, wanting to space child birth, not wanted by the partner, being too young and having completed family size were the other common reasons for regarding the pregnancies as unintended found in our study. These were similar to the findings by Oye-Adeniran et al. (2004).

The study showed that there was a relationship between pregnancy intention and the women's age, age at marriage, education, place of residence, knowledge of sex education and contraceptive use. The risk of experiencing unintended pregnancy was found in our study to be higher at the extremes of maternal age (less than 20 years of age and 40 years of age and above) though it was not statistically significant. The women that were less than 20 years of age were likely to be unmarried adolescents basking in youthful exuberance with limited knowledge about sex and access to family planning services (Mutumbi, 2013; Geda \& Lako, 2011). The women that were 40 years and above were more likely to have completed their family size and may not be using any or appropriate method of family planning (Mutumbi, 2013; Izugbara, 2014; Geda \& Lako, 2011). Also, some premenopausal women may wrongly believe that they were no longer fertile and as such there would be no need for contraception only to be surprised by the occurrence of unintended pregnancy (Mutumbi, 2013; Geda \& Lako, 2011). These findings were in consonance with the findings from previous studies (Mutumbi, 2013; Izugbara, 2014; Geda \& Lako, 2011).

The age at marriage was a significant determinant of the pregnancy intention. Unintended pregnancies were higher in those women that got married before 18 years compared with those that were married at 18 years of age and 
above. This was similar to the findings in Ethiopia (Geda \& Lako, 2011; Solomon \& Mesganaw, 2006). This could be because those who were married before 18 years were more likely to have entered into marriage when they were not physically, psychologically and economically prepared to have pregnancies (Mutumbi, 2013; Geda \& Lako, 2011; Solomon \& Mesganaw, 2006). They were also likely to be less educated, less financially empowered and therefore less autonomous in making reproductive decisions (Mutumbi, 2013; Geda \& Lako, 2011; Solomon \& Mesganaw, 2006). As such, they were more likely to be influenced by their husbands, families and culture with respect to decision on the timing and intention of their pregnancies (Geda \& Lako, 2011).

The relationship between education and pregnancy intention has been inconsistent from previous studies (Mutumbi, 2013; Palamuleni \& Adebowale, 2014; Ikamari et al., 2013; Habte, Teklu, Melese, \& Magafu, 2013; Izugbara, 2014; Geda \& Lako, 2011; Faye et al., 2013; Goto, Yasumura, Reich, \& Fukao, 2002; Geelheod, Nayembil, Asare, van Leeuwen, \& van Roomalen, 2002; Kassa, Berhane, \& Worku, 2012). However, our study showed that the level of education was a significant determinant of pregnancy intention. The likelihood of having unintended pregnancy was highest among those with no formal education where more than two-thirds of them had unintended pregnancy and decreased with higher educational attainment. As such, the women with tertiary education had lowest percentage of unintended pregnancy with only one-fourth of them reporting having had unintended pregnancy. This could be because educated women were more likely to delay their first childbirth, limit their family size, space their childbirth and have stronger motivation for correct and consistent use of contraception (Mutumbi, 2013; Geda \& Lako, 2011).

Furthermore, another important determinant of pregnancy intention was the place of residence. Our study showed that women that lived in rural areas had more unintended pregnancies than those that lived in urban areas. This was similar to the finding of Mutumbi in Zambia (Mutumbi, 2013). This could be attributed to ignorance, illiteracy, poverty, higher fertility rate, limited availability of health services, and poor utilization of social and health services that characterize rural areas (Mutumbi, 2013).

Knowledge of sex education was an important determinant of pregnancy intention. Those women that received sex education were less likely to have unintended pregnancy. This is because knowledge of sex education would help them refrain from unwholesome sexual practices that might culminate in unintended pregnancies. Knowledge of sex education could do this by facilitating abstinence and correct and consistent use of condom.

Contraceptive use was a significant determinant of unintended pregnancy. Those women that had used or were using one form of contraceptive method or the other were less likely to have unintended pregnancies (Sudhinaraset, 2008). This is because any contraceptive method irrespective of its effectiveness reduces the chances of pregnancy. However, those that used modern contraceptive method had lower unintended pregnancies compared to those that used natural method because of their higher efficacy.

\section{Conclusion}

Unintended pregnancy is a common public health menace in our environment. Its prevention requires collaborative efforts of individuals, families, governmental and non-governmental agencies. It entails public enlightenment on wholesome sexual practices and the dangers of unintended pregnancies. Also inculcating sex education into the secondary and tertiary schools' curricula is pertinent to stemming the tide of unintended pregnancies. The provision of free or affordable contraceptive services especially in rural areas will be instrumental to reducing the prevalence and scourge of unintended pregnancies.

\section{Limitation of The Study}

There are some limitations to the interpretation of the results of this study. The major limitation arises from the study design. The research was a cross-sectional study of women's pregnancy intention in previous and index pregnancies. As such the probability of recall bias and misreporting of events might occur. Also, some socio-cultural and religious factors may affect patient willingness to disclose her pregnancy intention.

\section{Acknowledgements}

We are grateful to the hospital management for giving us the permission to carry out the study in our hospital.

\section{Competing Interests Statement}

The authors declare that there are no competing or potential conflicts of interest.

\section{References}

Faye, C. M., Speizer, I. S., Fosto, J. C., Corroon, M., \& Koumtingue, D. (2013). Unintended pregnancy: magnitude and correlates in six urban sites in Senegal. Reprod Health, 10, 59. https://doi.org/10.1186/1742-4755-10-59 
Finer, L. B., \& Zolna, M. R. (2011). Unintended pregnancy in the United States: Incidence and disparities. Contraception, 84(5), 478-485. https://doi.org/10.1016/j.contraception.2011.07.013

Geda, N. K., \& Lako, T. K. (2011). A population based study on unintended pregnancy among married women in a district in Southern Ethiopia. J Geogr Reg Plann 2011; 4(7): 417- 27.

Geelheod, D., Nayembil, D., Asare, K., van Leeuwen, J. H. S., \& van Roomalen, J. (2002). Gender and unwanted pregnancy: a community-based study in rural Ghana. J Psychosom Obstet Gynaecol., 23(4), 249-55. https://doi.org/10.3109/01674820209074679

Goto, A.,Yasumura, S., Reich, M. R., \& Fukao, A. (2002). Factors associated with unintended pregnancy in Yamagata, Japan. Soc Sci Med., 54(7), 1065-79. https://doi.org/10.1016/S0277-9536(01)00081-8

Habte, D., Teklu, S., Melese, T., \& Magafu, M. G. (2013). Correlates of unintended pregnancy in Ethiopia: Results from a National Survey. PLoS One, 8(12), e82987. https://doi.org/10.1371/journal.pone.0082987

Ikamari, L., Izugbara, C., \& Ochako, R. (2013). Prevalence and determinants of unintended pregnancy among women in Nairobi, Kenya. BMC Pregnancy Childbirth, 13, 69. https://doi.org/10.1186/1471-2393-13-69

Izugbara, C. (2014). Household characteristics and unintended pregnancy among ever-married women in Nigeria. Soc Med 2014; Vol. 8 No 1.

Kassa, N., Berhane, Y., \& Worku, A. (2012). Predictors of unwanted pregnancy in Kersa, Eastern Ethiopia. Reprod Health, 9, 1. https://doi.org/10.1186/1742-4755-9-1

Mutumbi, Z. (2013). The prevalence, determinants and outcomes of women with unintended pregnancies delivering at the University Teaching Hospital, Lusaka (MSc dissertation. The University of Zambia, Lusaka; 2013). Retrieved

from http://www.dspace.unza.zm:8080/xm/ui/bitstream/handle/123456789/3241/main\%20body.pdf?sequence=1. Accessed on 05-01-2015.

Naing, L., Winn, T., \& Rusli, B. N. (2006). Practical issues in calculating the sample size for prevalence studies. Arch Orofac Sci, 1, 9-14.

National Population Commission (Nigeria) and ICF International. (2014). Nigeria Demographic and Health Survey 2013. Rockville, Maryland, USA: National Population Commission and ICF International 2014.

Oye-Adeniran, B. A., Adewole, I. F., Umoh, A. V., Ekanem, E. E., Gbadegesin, A. et al. (2004). Community-based survey of unwanted pregnancy in southwestern Nigeria. Afr $J$ Reprod Health, 8(3), 103-115. https://doi.org/10.2307/3583397

Palamuleni, M. E., \& Adebowale, A. S. (2014). Prevalence and determinants of unintended pregnancies in Malawi. Etude Popul Afr, 28(1). https://doi.org/10.11564/28-1-507

Solomon, W., \& Mesganaw, F. (2006). Unintended pregnancy and induced abortion in a town with accessible family planning services: the case of Harar in eastern Ethiopia. Ethiop J Health Dev, 20(2), 79-83.

Sudhinaraset, M. (2008). Reducing unsafe abortion in Nigeria. In Brief, New York. Guttmacher Institute, 2008, No 3.

\section{Copyrights}

Copyright for this article is retained by the author(s), with first publication rights granted to the journal.

This is an open-access article distributed under the terms and conditions of the Creative Commons Attribution license (http://creativecommons.org/licenses/by/4.0/). 